\title{
Constitution and Partial Structure of Group Lipoids*
}

\author{
By \\ Hajime Masamune, Tugio Maehara, Sen-itiroh Hakomori

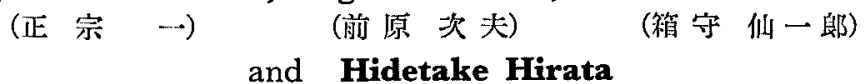 \\ (本田英武) \\ From the Medico-chemical Institute, Tohoku University, Sendai
}

(Received for publication, September 1, 1953)

Group lipoids, prepared from human livers (Group A) and hog lungs in practically pure state, were saponified with $0.2 \mathrm{~N} \mathrm{NaOH}$. From each of them were obtained four fractions. Fr. I was a higher aliphatic alcohol; Fr. II contained palmitic acid and Fr. III several amino acids and $\alpha$-glycerophosphoric acid; Fr. IV was a partial group lipoid, that proved homogeneous after electrophoresis. On the final fraction of the group lipoids further studies were made with following results: a) The group-active fragment of the human liver group lipoid consisted of 2 molecules of $\alpha$-glycerophosphoric acid, $1 \sim 2$ molecules of ethanolamine (differing according to the preparation), 2 molecules of glutamic acid, 1 molecule each of glycine and serine, 4 molecules of galactose, 2 molecules each of mannose and chondrosamine, and a few fatty acids, and that of the hog lung group lipoid of 4 molecules of $\alpha$-glycerophosphoric acid, 1 molecule each of aspartic acid and ethanolamine, 2 molecules each of serine and glutamic acid, 4 molecules of galactose, 1 molecule each of glucosamine and chondrosamine, and a water-insoluble matter. b) i) The fragment of the human liver group lipoid was studied with DNFB, and glycine, one of the molecules of ethanolamine and the both chondrosamine molecules were found to contain a free amino group. ii) The same material gave more vivid ninhydrin reaction at $\mathrm{pH}$ 's from 3 to 5 than at $\mathrm{pH} 7$ when exposed preliminarily to the respective $\mathrm{pH}$ 's at $50^{\circ} \mathrm{C}$, and became to retain more of cupric ion or azocarmine in retention analysis when heated in advance with a dilute acetic acid of $\mathrm{pH} 1 \sim 2$. It reduced Fehling solution but not a $\mathrm{HgCl}_{2}$ solution of $\mathrm{pH}$ 7.5 8.0. The findings suggested the presence of a $\mathrm{N}$-glycoside linkage in the molecule, so it was heated with $1 \mathrm{~N}$ acetic acid after once pairing with DNFB and then again treated with DNFB followed by HCl-hydrolysis. The DNP derivative of glutamic acid was detected among the acid-hydrolysis products. Therefore, this amino acid is suspected to partake in forming the $\mathrm{N}$ glycoside link.

* Details were read before the 25th General Meeting of the Japanese Biochemical Society, Tokyo, April 26-28, 1953. 